\title{
Determinants of Treatment Failure Among Tuberculosis Patients on Directly Observed Theraphy in Rural Primary Health Care Centres in Ogun State, Nigeria
}

\section{Amoran OE*}

Department of Community Medicine and Primary Care, College of Health Sciences, Olabisi Onabanjo University Teaching Hospital, Sagamu, Nigeria

\begin{abstract}
Introduction: Poor compliance with treatment (default) is thus a major impediment to effective tuberculosis (TB) chemotherapy worldwide even though free medication may be available, many patients may not be successfully treated. This study was designed to identify risk factors associated with treatment failure during TB treatment within the National Tuberculosis and Leprosy Control Programme [NTBLCP programme] in rural primary health care centres in Nigeria.
\end{abstract}

Methods: This study is a retrospective, cohort study. The information was collected from the facility record using a data collection form. A cohort of all TB patients attending clinic for treatment from $1^{\text {st }}$ April 2004 to $30^{\text {th }}$ June 2007 was used. A total sample of 938 patients was reviewed.

Result: The overall treatment failure rate among the TB patients was $5.0 \%$ and $[15.4 \%]$ of the entire negative outcome. In all, 749 [79.9\%] of cases completed treatment and were cured, 135 (14.4\%) defaulted, 47[5.0\%] had treatment failure and $27(2.9 \%)$ of cases were transferred out. Predictors of treatment failure were Relapse after previous treatment $[R R=2.41, C . I=1.21-4.81]$ and far distance of domicile from $P H C$ centre $[R R=6.9, C . I=2.15-22.18]$. There was no statistically significant difference in treatment failure between HIV positive and HIV negative TB patients $[R R=2.65, C . I=0.63-11.09]$, cases transferred in $[R R=2.24, C . I=0.35-14.55]$ and age (children $R R=1.48, C . I=0.78-$ 2.42]).

Conclusion: The previous treatment failure category presented with lower risk of current failure and better favourable outcome than cases of relapse suggesting that most of these failure might have been due to logistic failure rather than multi-drug resistance strain. This study indicates that National TB control programmes should pay a closer attention to stricter monitoring of patients that are transferred-in or relapse and are coming from far distances from $\mathrm{PHC}$ in order to prevent multi-drug resistant tuberculosis in rural African populations.

\section{Introduction}

Tuberculosis (TB) is a chronic infectious disease caused by Mycobacterium tuberculosis and occasionally by Mycobaterium bovis and Mycobaterium africanuum. Despite the progress in tuberculosis (TB) control, the failure of treatment mainly due to non-adherence to medical recommendations remains a major obstacle to the eradication of this disease in both industrialized and developing countries [1]. In Nigeria, tuberculosis is a serious public health problem. Nigeria is ranked $4^{\text {th }}$ among the $22 \mathrm{~TB}$ high Burden Countries (HBC) in the world and highest in Africa. The morbidity and mortality as a result of TB has contributed to the impoverishment of millions of families and even whole nations and if the present trend is allowed to continue, it is likely that no other infectious disease will create as many orphans and devastate as many families as TB [2]. In India, only $30 \%$ of tuberculosis (TB) patients receiving conventional treatment and 52\% receiving short-course chemotherapy (SCC) completed the treatment. Incompletely cured patients return to the community, and each sputum-positive case can infect 10-14 people in the course of a year [3].

Direct monitoring of chemotherapy is a must for success. Without support throughout the full course of treatment, many patients with tuberculosis adhere to treatment until symptoms have resolved and then interrupt or default in treatment. These patients may equate disease with symptoms and therefore the need to continue treatment after the symptom has resolved may not be seen as necessary. Despite the progress in tuberculosis (TB) control, the failure of treatment mainly due to non-adherence to medical recommendations remains a major obstacle to the eradication of this disease in developing countries.
The likelihood of successful treatment of tuberculosis assuming an appropriate drug regimen is prescribed depends on the extent to which patients complete the prescribed treatment regimen; usually called compliance with, or adherence to treatment [1].

High rates and transmission of multidrug-resistant (MDR) tuberculosis (TB) have been associated with the Mycobacterium tuberculosis complex (MTBC) pointing to the importance of pathogen genetic factors for the modulation of infection outcome and epidemiology. Higher rates among previously treated and Multi-drug resistant tuberculosis patients (MDR TB) point to a higher potential to escape therapy and develop MDR TB $[4,5]$. Failure of treatment, relapse, death, and drug resistance, threaten not only patients but also communities. Compliance with the drug treatment is hence crucial and is directly linked to the treatment outcome.

The morbidity and mortality as a result of TB has contributed to

*Corresponding author: Amoran OE, Department of Community Medicine and Primary Care, Olabisi Onabanjo University Teaching Hospital, Sagamu, Nigeria, E-mail: drfamoran@yahoo.com

Received November 16, 2011; Accepted December 22, 2011; Published December 24, 2011

Citation: Amoran OE (2011) Determinants of Treatment Failure Among Tuberculosis Patients on Directly Observed Theraphy in Rural Primary Health Care Centres in Ogun State, Nigeria. Primary Health Care: Open Access 1:104. doi:10.4172/2167-1079.1000104

Copyright: (c) 2011 Amoran OE. This is an open-access article distributed under the terms of the Creative Commons Attribution License, which permits unrestricted use, distribution, and reproduction in any medium, provided the original author and source are credited. 
the impoverishment of millions of families and even whole nations and if the present trend is allowed to continue, it is likely that no other infectious disease will create as many orphans and devastate as many families as TB. The likelihood of successful treatment of tuberculosis, (assuming an appropriate drug regimen is prescribed), depends on the extent to which patients complete the prescribed treatment regimen (usually called compliance with, or adherence to treatment). Anti-tuberculosis drug regimens consist of multiple drugs given for a minimum of six months [6]. Commonly, treatments of this sort are inconsistent with the patient's cultural milieu, belief system and living circumstances. Consequently, it is not surprising that, without appropriate treatment support, significant proportions of patients with tuberculosis discontinue treatment before completion of the planned duration or are erratic in drug taking (so called default).

Mycobacterium tuberculosis has shown a propensity to mutate toward drug resistance, and defaulting patients have delayed sputum conversion and almost invariably relapse, often with a drug resistant strain, thus increasing the cost of treatment and may eventually lead to death. Retreatment requires more expensive drugs producing a greater financial burden on either the patient or public health delivery system. Many DOTS experiences in developing countries have been reported $[2,7,8]$. However, experiences with treatment failure in rural primary health care facilities are limited. For instance, in the present study, we sought to describe the experience of tuberculosis according to the NTLCP in a rural zone in Nigeria over a period of 3 years (2004 to 2007). This study was designed to identify risk factors associated with treatment failure during TB treatment within the NTBLCP programme. However further studies will be needed to establish these findings.

\section{Materials and Methods}

\section{Study design}

This study is a retrospective, cohort study. The information was collected from the facility record using a data collection form. A cohort of all TB patients attending clinic for treatment from $1^{\text {st }}$ April 2004 to $30^{\text {th }}$ June 2007 was used.

\section{Study location}

There are 20 LGAs in Ogun State with each LGA having a TB and leprosy supervisor and one central register for each LGA. This study was carried out at the PHC Units in the ljebu North Local Government Area of Ogun State. The biggest town is ljebu-lgbo town which is a semi-urban settlement. All other towns in the area where the PHC were located are rural settlements with an estimated population of 207, 969 people (projections from 1991 population census). It occupies an area of 969 square kilometers with an average density of 215 persons per square kilometer. The predominant tribe is Yoruba with ljebu people in the majority. The major occupations of the people are trading and farming. There are nine tuberculosis and leprosy control clinics in the LGA located at Obada PHC, Ago Iwoye/Ibipe PHC, Ago Iwoye / Oke-Odo PHC, Oke Agbo PHC, Oru/Awa/Ilaporu PHC, OOU Health Centre, Oru Refugee Camp, Apoje PHC, with a leprosy settlement center loctated at Oke Eriwo. A central register for all the PHC units is kept at the Obada PHC unit. The TBL supervisor for the Local Government co-ordinates the activities of all the TBL centers. The German Leprosy and TB Relief Association (GLRA) is responsible for the provision of free drugs for the programme.

\section{Sampling method}

A total sample of all patients diagnosed with and receiving treatment within the PHC units of the NTBLCP programme in ljebu North LGA between $1^{\text {st }}$ April, 2003 and June 2007, including those transferred in from other LGA were enrolled in the study.

\section{Diagnosis of TB}

Persons suspected of having $\mathrm{TB}$ are referred to $\mathrm{TB}$ clinics at district health centers or to the TB clinic at the general hospital for a standardized evaluation, including history and physical examination, examination of three sputum specimens for AFB, and, if AFB smearnegative, chest radiography. TB diagnosis and classification follow standard WHO definition [5]. All persons diagnosed with TB in these facilities undergo HIV counseling and testing if available in the centre. A rapid serological test is performed in the TB clinic. HIV testing in the laboratory is by enzyme-linked immunosorbent assay followed by two different HIV ELISA tests if the first is positive. The tests used varied over the time of this project.

In addition to routine clinical records and standardized $\mathrm{TB}$ registers, TB clinics also maintain a separate register of $\mathrm{HIV}$-infected TB patients. Patient who have a positive retroviral screening test result are sent to the nearest teaching hospital. The Olabisi Onabanjo University Teaching Hospital for a confirmatory test and commencement of antiretroviral Therapy (ARV), if required.

\section{Data collection}

We retrospectively reviewed $\mathrm{TB}, \mathrm{HIV}$, and $\mathrm{TB} / \mathrm{HIV}$ registers and clinical records to collect data about all HIV-infected TB patients aged $\geq 15$ years diagnosed in ljebu North LGA between $1^{\text {st }}$ April, 2003 and June 2007, including those transferred in from other LGA. The support and assistance of the NTBLCP programme officer for Ogun state was enlisted through an advocacy visit to his office, who in turn linked up with the; TBL supervisor for the Ijebu North LGA to ensure an unfettered access to patient register. Data were abstracted from these records using a standardized form that included questions about personal and demographic history; HIV risk factors, conditions, and treatment; TB diagnostic studies, treatment history, and treatment outcomes. Public health staffs were trained to complete the abstraction form, and forms were checked for completeness and accuracy by a data collection supervisor.

\section{Definitions of Data for Analysis}

We used standard WHO definitions for TB disease classification, registration and treatment outcome categories $[15,16]$. TB registration status was divided into "new, treatment after relapse, treatment after failure, treatment after default or "transfer in". Final TB treatment outcome was divided into "successful, failure, death, or default or transferred out. A successful treatment outcome included cured or completed;

\section{Inclusion criteria}

(1) Patients were included in this study if they belonged to a cohort of patient who were diagnosed with tuberculosis, and received treatment within the framework of the NTBLCP in ljebu North LGA between $1^{\text {st }}$ April 2003, and 30 ${ }^{\text {th }}$ June, 2007 irrespective of the treatment outcome. 
(2) Patients who completed their treatment within the periods of study.

(3) Also, all patient who were transferred into the TB programme of the LGA from PHC units in other LGAs of the state or from another state are included with an accurate recording of their initial registration data from the primary PHC (referral) units.

(4) The study included all PTB patients (whether sputum smears positive or sputum smear negative) and also all extrapulmonary TB cases. Cases diagnosed clinically e.g. chronic cough, Chest X-ray etc still had sputum smear examinations and were labelled based on their sputum smear status

(5) Extra-pulmonary cases are clinically diagnosed and recommended for treatment by a clinician.

\section{Data analysis}

To describe patient characteristics, we calculated proportions and medians. For categorical variables, we compared proportions using chisquare tests and, when appropriate, Fisher's exact test. For continuous variables, we compared medians using the Wilcoxon Rank-Sum Test and evaluated trends using chi-squared test for trend.

In bivariate analysis, we analyzed risk factors for mortality by age, sex, HIV infection, and residence in a rural district, adverse event during TB treatment, TB smear status, disease location, TB types, and registration status. Chi-square was used to determine association between caterorical variables and a p value of less than 0.05 was considered significant. Data was presented in tabular form.

\section{Ethical considerations}

Ethical clearance was obtained from the Olabisi Onabanjo Teaching Hospital Ethics Board. Confidentiality on candidate's information was maintained. Permission of the State Ministry of Health, NTBLCP programme officer for Ogun state and TBL supervisor for the Ijebu North LGA were obtained before the commencement of the study.

\section{Result}

A total sample of 938 patients diagnosed with and receiving treatment within the PHC units of the NTBLCP programmer in ljebu North LGA between $1^{\text {st }}$ April, 2003 and June 2007, were included in the study. Of these, 464 (49.5\%) were males. The age ranged from 1 to 83 years, (mean $36.67 \pm 16.4$ years). The weight range at presentation was between 9 to $98 \mathrm{~kg}$ (mean $48.5=12.1 \mathrm{~kg}$ ). Treatment failure was highest [7.0\%] among the children. However there is no statistically significant difference in failure rate among the various age groups $[\mathrm{p}=0.823$ ]. The overall treatment failure rate among the TB patients was $5.0 \%$.This was $15.4 \%$ of the total negative outcome in the management of TB patients using the DOTS strategies. There was no significant difference in treatment failure rate between male and female patients (5.8\% vs $4.2 \%, \mathrm{p}=0.261$ ). Children were however at a relatively higher risk of developing failure $[R R=1.48, C . I=0.71-3.09]$. Table 1 shows the treatment failure rate and their distribution by sex and age-groups with relative risk values.

Table 2 presents other factors associated with treatment failure. In all, 749 [79.9\%] of cases completed treatment and were cured, 135 (14.4\%) defaulted, 47 [5.0\%] had treatment failure and 27 (2.9\%) of cases were transferred out. The TB/HIV Collaborative project whereby

\begin{tabular}{|l|c|c|c|c|}
\hline & $\begin{array}{c}\text { Total } \\
\text { No (\%) }\end{array}$ & $\begin{array}{c}\text { Failure Rate } \\
\text { No (\%) }\end{array}$ & $\begin{array}{c}\text { Relative } \\
\text { Risk }\end{array}$ & $\begin{array}{c}\text { Confidence } \\
\text { Interval }\end{array}$ \\
\hline Age & \multicolumn{5}{|l|}{} \\
\hline 0-15 yrs & $114(12.2)$ & $8[7.0]$ & 1.48 & $0.71-3.09$ \\
\hline $15-30$ yrs & $303(32.3)$ & $16[5.3]$ & 1.08 & $0.6-1.95$ \\
\hline $31-45$ yrs & $218[23.2]$ & $10[4.9]$ & 0.89 & $0.45-1.77$ \\
\hline $46-60$ yrs & $130[13.9]$ & $5[3.8]$ & 0.74 & $0.3-1.84$ \\
\hline$>60$ yrs & $173[18.4]$ & $8[4.6]$ & 0.91 & $0.43-1.91$ \\
\hline Total & 938 & $47[5.0]$ & & \\
\hline Sex & {$[100.0]$} & & & \\
\hline Male & $464[49.5]$ & $27[5.8]$ & 1.38 & $0.78-2.42$ \\
\hline Female & $474[50.5]$ & $20[4.2]$ & 1.00 & \\
\hline Location of Domicile & & & \\
\hline 0-5 km Radius & $626[66.7]$ & $32[5.1]$ & 1.06 & $0.58-1.93$ \\
\hline 6-10 km Radius & $306[32.6]$ & $13[4.2]$ & 0.77 & $0.41-1.43$ \\
\hline$>10 \mathrm{~km}$ Radius & $6[0.6]$ & $2[33.3]$ & 6.9 & $2.15-22.18$ \\
\hline
\end{tabular}

Table 1: Treatment Failure Rate and Socio-demographic Characteristics.

\begin{tabular}{|l|c|c|c|c|}
\hline & $\begin{array}{c}\text { Total } \\
\text { No (\%) }\end{array}$ & $\begin{array}{c}\text { Failure } \\
\text { Rate } \\
\text { No (\%) }\end{array}$ & $\begin{array}{c}\text { Relative } \\
\text { Risk }\end{array}$ & $\begin{array}{c}\text { Confidence } \\
\text { Interval }\end{array}$ \\
\hline Categories of Patient & $743[79.3]$ & $30[4.0]$ & 0.46 & $0.26-0.82$ \\
\hline New Patients & $84[9.0]$ & $9[10.7]$ & 2.41 & $1.21-4.81$ \\
\hline Relapse & $80[8.5]$ & $5[6.3]$ & 1.27 & $0.52-3.13$ \\
\hline Return after Default & $9[1.0]$ & $1[11.1]$ & 2.24 & $0.35-14.55$ \\
\hline Transfer-in & $22[2.3]$ & $2[9.1]$ & 1.05 & $0.4-7.15$ \\
\hline Previous Treatment Failure & & & & \\
\hline HIV Status & $119[73.9]$ & $15[12.6]$ & 2.65 & $0.63-11.01$ \\
\hline Negative & $42[26.1]$ & $2[4.8]$ & 1.00 & \\
\hline Positive & $908[96.8]$ & $45[5.0]$ & 0.74 & $0.19-2.92$ \\
\hline Pre-Treatment Sputum Status & $17[1.8]$ & $2[11.8]$ & 2.41 & $0.64-9.13$ \\
\hline Sputum Positive & $13[1.4]$ & $1[0.07]$ & 1.00 & \\
\hline Sputum Negative & & & \\
\hline Extra-Pulmonary & &
\end{tabular}

Table 2: Factors associated with treatment failure.

tuberculosis patients were simultaneously offered VCCT for HIV was commenced in the last quarter of the study. A lot, 777 (82.8\%) of the subjects were not offered the services. Of the 161 patients who were offered such services $42(26.1 \%)$ was HIV positive. Only $4.8 \%$ of those who had treatment failure and were offered VCCT were HIV positive. There is however no statistically significant relationship between HIV and treatment failure $(\mathrm{P}=0.126)$.

Treatment failure rate was significantly higher among relapse patients $[\mathrm{RR}=2.41$, [ C.I $=1.21-4.81]$ who presented at the primary health care centres when compared with other categories of patients on treatment such as transfer-in new patients [4.0\%], return after default [6.3\%] and those with previous treatment failure [4.4\%] $(\mathrm{X} 2=36.4$, $\mathrm{p}=0.062)$. Treatment failure was not significantly associated with positive pre-treatment sputum microscopy and negative pre-treatment sputum among the TB patient in this study [11.8\% vs $5.0 \%, \mathrm{p}=0.313]$ (Table 2). Furthermore majority of the patient that had treatment failure was noted at 5-6months of presentation at the PHC centres [p=0.003].

However distance from PHC centre was significantly associated with treatment failure among the TB patient in this study. Those living more than $10 \mathrm{~km}$ from $\mathrm{PHC}$ centre are more likely to defect thus developing treatment failure $[R R=6.9$, C.I=2.15-22.18]. 


\section{Discussion}

The treatment failure rate in our study was 5.0\%. This is higher than those reported previously by several similar studies [9-10]. However similar result have been obtained in Nigeria and other African countries $[11,12]$. Treatment failure was highest $[7.0 \%]$ among the children. This study suggests that children are high risk group for treatment failure in an African population and should be paid more attention.

This study shows a success rate of $79.9 \%$.This is lower than the WHO recommended rate of $85 \%$ The study indicates that much health education still needs to be done at the PHC centres and the community to sensitize the community members on the need for treatment adherence in the management of $\mathrm{TB}$ and other chronic illnesses. Strategies for behavoural changes targeted at cultural practices on health that do not encourage adherence to treatment in this African population should be employed.

Patients who had a relapse of TB infection and those transferred in had a significantly higher failure rate when compared with other categories of patient on treatment. Several studies had reported that factors such as relapse, treatment failure and prior imprisonment are major factors responsible for transmission in high incidence communities [13-15]. Furthermore, it shows that an overwhelming majority of cases in high-incidence setting is probably due to recent re-infection. The previous treatment failure category presented with lower risk of current failure and better favourable outcome this suggest that most failure might have been due to logistic failure such as loss of potency of drugs, expired drugs, fake drugs, non compliance to treatment regimen etc rather than multi-drug resistance strains. Similar observations have been made by other studies [16]. However, higher rates among previously treated and MDR TB patients point to a higher potential to escape therapy and develop MDR TB [17]. Failure of treatment, relapse, death, and drug resistance, threaten not only patients but also communities $[18,19]$. Compliance with the drug treatment is hence crucial and is directly linked to the treatment outcome.

HIV infection was not significantly associated with treatment failure in this study. HIV test was not required for TB cases in Ijebu North LGA until October 2006 when VCCT was introduced into the management of TB. The period of about one year used to monitor HIV shows that HIV is not a major factor in TB treatment failure though this may not be conclusive. However, some studies have suggested that $\mathrm{HIV}$ is the strongest predictor of progression from latent TB infection to active disease [20-24]. The emergencies of more interaction of TB with human immunodeficiency virus (HIV) infection might be one of the reasons. HIV has contributed to a global resurgence of tuberculosis and the development and transmission of MDR TB [25].

However distance from PHC centre was significantly associated with treatment failure among the TB patient in this study. Those living more than $10 \mathrm{~km}$ from PHC centre are more likely to defect thus developing treatment failure. The DOTS strategy adopted by the Nation specifies that patients are selected for treatment based on location of residence from the PHC [1]. This confirms the importance of enforcing this criterion in the management of TB in Nigeria and other African populations especially in the rural areas in order to prevent treatment failure. It is not obviously clear how this is related, cultural and financial factors may play a critical role in this relationship. Formation of close ties which encourage cross transmission of MDR TB may also play an important role [26]. However further studies will be needed to establish these findings.

The study concludes that the previous treatment failure category presented with lower risk of current failure and better favourable outcome than cases of relapse suggesting that most of these failure might have been due to logistic failure rather than multi-drug resistance strain. This study indicates that National TB control programmes should pay a closer attention to stricter monitoring of patients that are transferred-in or relapse and are coming from far distances from PHC in order to prevent multi-drug resistant tuberculosis in African populations.

This study has several major limitations. It was retrospective and based only on data that was available in clinical and public health records. We could not independently verify the accuracy of these records, nor could we collect additional data needed to confirm or refute our findings. This impacts variables such as those measuring the presence of an adverse event. We have no detail information of every patient in this study. However, this is beyond our control. Also, because of the difficulty of contacting the defaulters, our study could not address some of the factors leading to default. Further studies to explore the various factors involved in irregular $\mathrm{TB}$ treatment are needed. Nevertheless, our findings are applicable to the current situation of TB control in rural Nigeria and African population, and may draw attention to major factors influencing treatment failure in the management and control of TB.

\section{References}

1. World Health Organization. Secular trend of tuberculosis in Western Europe Epidemiological situation in countries. WHO/TB/1992, Geneva.

2. Federal Ministry of Health. National tuberculosis and Leprosy Control Programme. 2006-2010 Strategic Plan for Tuberculosis Control Programme in Nigeria 2005.

3. Sudarshan H, Sridharan S (1995) Tuberculosis control programme in rural area: experiences from the field. Health Millions 21: 49-52.

4. Singh V, Jaiswal A, Porter JD, Qgden JA, Sarin R, et al. (2002) TB control poverty and Vulnerability in Delhi, India. Trop Med Int Health 7: 693-700.

5. World Health Organization (2008) Global tuberculosis control: surveillance planning and financing: WHO Report 2008. Geneva, Switzerland: WHO.

6. World Health Organisation (2003) Treatment of tuberculosis: Guidelines for national programmes. Geneva, Switzerland: World Health Organization; 2003.

7. El Sony Al, Khamis AH, Enarson DA, Baraka O, Mustafa SA, et al. (2002) Treatment results of DOTS in 1797 Sudanese tuberculosis patients with or without HIV co-infection. Int J Tuberc Lung Dis 6: 1058-1066.

8. Kassu A, Mengistu G, Ayele B, Diro E, Mekonnen F, et al. (2007) HIV and intestinal parasites in adult TB patients in a teaching hospital in Northwest Ethiopia. Trop Doct 37: 222-224.

9. Yassin MA, Datiko DG, Shargie EB (2006) Ten-year experiences of the tuberculosis control programme in the southern region of Ethiopia. Int $\mathrm{J}$ Tuberc Lung Dis 10: 1166-1171.

10. Shargie EB, Lindtjørn B (2005) DOTS improves treatment outcomes and service coverage for tuberculosis in South Ethiopia: a retrospective trend analysis. BMC Public Health 5: 62.

11. Peters EJ, Ekott JU, Eshiat GA, Anyanechi CC (2005) Tuberculosis in Calabar: a ten years review 1994-2003. Niger J Med 14: 381-385.

12. Harries AD, Nyong 'Onya L, Salampon FM, Nyangulu DS, Veen J, et al. (1996) Tuberculosis programme changes and treatment outcome on patients with 
Citation: Amoran OE (2011) Determinants of Treatment Failure Among Tuberculosis Patients on Directly Observed Theraphy in Rural Primary Health Care Centres in Ogun State, Nigeria. Primary Health Care: Open Access 1:104. doi:10.4172/2167-1079.1000104

smear positive pulmonary tuberculosis in Blantyre Malawi. Lancet 347: 807809 .

13. Tekle B, Mariam DH, Ali A (2002) Defaulting from DOTS and its determinants in three districts of Arsi Zone in Ethiopia. Int J Tuberc Lung Dis 6: 573-579.

14. Santha T, Garg R, Frieden TR, Chandrasekaran V, Subramani R, et al. (2002) Risk factors associated with default, failure and death among tuberculosis patients treated in a DOTS programme in Tiruvallur District, South India, 2000. Int J Tuberc Lung Dis 6: 780-788.

15. Michael KW, Belachew T, Jira C (2004) Tuberculosis defaulters from the "dots" regimen in Jimma zone, southwest Ethiopia. Ethiop Med J 42: 247-253.

16. Shabi AR, Agarwa Sk, Shard KV (2002) Study of drug resistance in previously treated tuberculosis patients in Gujarat, India. Int J Tuberc lung Dis 6: 10981101.

17. Noeske J, Nguenko PN (2002) Impact of resistance to anti-tuberculosis drugs on treatment outcome using WHO standard regime. Trans R Soc trop Med Hyg 96: 429-433.

18. Barn TS, Gunreberg C, chamroonsawasdi k, Bam DS, Aalberg O, et al. (2006) Factors affecting patient adherence to DOTS in urban kathmaradu Int $\mathrm{J}$. Tubarching Dis 10: 270-276.

19. Espinal MA, kim SJ, Suarez PG, Buez J, Kochi A, et al. (2000) Standard short course chemotherapy for doing resistance tuberculosis JAMA 283: 2575-2576.
20. Oliveira HB, Marin-León L, Gardinali J (2005) Analysis of treatment outcomes related to the tuberculosis control program in the city of Campinas, in the state of São Paulo, Brazil. J Bras Pneumol 31: 133-138.

21. Hopewell PC (1992) Impact of human immunodeficiency virus infection on the epidemiology, clinical features, management, and control of tuberculosis. Clin Infect Dis 15: 540-547.

22. Raviglione MC, Snider DE Jr, Kochi A (1995) Global epidemiology of tuberculosis. Morbidity and mortality of a worldwide epidemic. JAMA 273: 220226

23. Anglaret X, Saba J, Perronne C, Lacassin F, Longuet $P$, et al. (1994) Empiric antituberculosis treatment: benefits for earlier diagnosis and treatment of tuberculosis. Tuber Lung Dis 75: 334-340.

24. Ruiz-Navarro MD, Espinosa JA, Hernández MJ, Franco AD, Carrillo CC, et al (2005) Effects of HIV status and other variables on the outcome of tuberculosis treatment in Spain. Arch Bronconeumol 41: 363-370.

25. Santha T, Garg R, Frieden TR, Chandrasekaran V, Subramani R, et al. (2002) Risk factors associated with default, failure and death among tuberculosis patients treated in a DOTS programme in Tiruvallur District, South India, 2000. Int J Tuberc Lung Dis 6: 780-788.

26. Qadeer I (1995) National tuberculosis programme: a social perspective. Health Millions 21: 10-13. 